\title{
Mediterranean diet and non-fatal acute myocardial infarction: a case-control study from Italy
}

\author{
Federica Turati ${ }^{1}$, Claudio Pelucchi ${ }^{1}$, Carlotta Galeone ${ }^{1}$, Delphine Praud ${ }^{1,2}$, \\ Alessandra Tavani ${ }^{1}$ and Carlo La Vecchia ${ }^{1,2, *}$ \\ 'Department of Epidemiology, IRCCS - Istituto di Ricerche Farmacologiche 'Mario Negri', Via La Masa 19, \\ 20156 Milan, Italy: ${ }^{2}$ Department of Clinical Sciences and Community Health, University of Milan, Milan, Italy
}

Submitted 25 October 2013: Final revision received 15 January 2014: Accepted 2 April 2014: First published online 19 May 2014

\begin{abstract}
Objective: To add epidemiological data on the association of adherence to the Mediterranean diet with non-fatal acute myocardial infarction (AMI) in a Southern European population.

Design: Hospital-based case-control study. Conformity to the traditional Mediterranean diet was assessed through a score (i.e. the Mediterranean diet score, MDS) based on nine dietary components (high consumption of vegetables, legumes, fruit and nuts, cereals, and fish and seafood; high ratio of monounsaturated to saturated lipids; low consumption of dairy and meat; and moderate alcohol consumption). The score ranged between 0 (lowest adherence) and 9 (highest adherence). The association of the MDS, or its components, with the risk of AMI was evaluated through multiple logistic regression models, controlling for potential confounding variables.

Setting: The study was conducted in the greater Milan area (Italy) between 1995 and 2003.

Subjects: Seven hundred and sixty patients with a first episode of non-fatal AMI and 682 controls.

Results: High consumption of vegetables and legumes were inversely associated with non-fatal AMI risk. As compared with MDS $<4$, the OR of non-fatal AMI were 0.85 (95\% CI $0.65,1 \cdot 12$ ) for MDS of $4-5$ and 0.55 (95\% CI $0.40,0.75$ ) for MDS $\geq 6$, with a trend in risk $(P<0 \cdot 01)$. Results were consistent in strata of selected risk factors and an apparently stronger association emerged for individuals with a lower BMI.

Conclusions: The Mediterranean diet is inversely associated with the risk of non-fatal AMI in this Southern European population.
\end{abstract}

The relationship between dietary factors and CHD has been a major focus of health research since the early 1960s, when Keys and Aravanis linked the lower incidence of CHD observed among Southern European populations to their traditional healthy eating pattern, i.e. the Mediterranean $\operatorname{diet}^{(1)}$. Several studies investigated the role of diet on CHD thereafter, providing evidence for a protective role of vegetables, nuts and MUFA (e.g. oleic acid, abundant in olive oil and nuts) and for a detrimental role of trans-fatty acids and foods with a high glycaemic load ${ }^{(2,3)}$. Moderate evidence supports a role of fish, marine $n-3$ fatty acids, folate, whole grains, dietary vitamins $\mathrm{E}$ and $\mathrm{C}, \beta$-carotene, low-to-moderate alcohol, fruits, fibre and flavonoids on CHD prevention ${ }^{(2)}$. Other selected dietary aspects have been evaluated in relation with $\mathrm{CHD}$, including $\alpha$-linoleic acid, SFA and PUFA, meat, eggs and milk, but findings are still uncertain $^{(2,3)}$. Scantier data are available on selected dietary patterns and CHD risk.
The main characteristics of the Mediterranean food pattern include a high consumption of plant foods (fruits, vegetables, legumes, wholegrain cereals and nuts) and fish; olive oil as the principal source of fat; relatively low consumption of meat and dairy products; and lowto-moderate consumption of wine, especially red wine, during meals. Adherence to the Mediterranean diet has been favourably related to all-cause mortality ${ }^{(4-6)}$, as well as to specific health outcomes, including cancer overall ${ }^{(6-9)}$ and at selected sites ${ }^{(10-13)}$, and cerebrovascular ${ }^{(14)}$ and cardiovascular diseases ${ }^{(2,6,15,16)}$. In particular, a meta-analysis of cohort studies estimated that a 2-point increase in a Mediterranean diet score was significantly associated with a $10 \%$ reduced risk of cardiovascular incidence or mortality ${ }^{(6)}$. There was however heterogeneity across results, definition of CHD and various Mediterranean diet scores.

With the aim of adding epidemiological data on this issue, we investigated the association between the 
Mediterranean diet and the incidence of non-fatal acute myocardial infarction (AMI), using data from a casecontrol study conducted in Italy.

\section{Methods}

\section{Study population}

Data were derived from a case-control study of non-fatal AMI, conducted in the greater Milan area, Italy, between 1995 and $2003^{(17,18)}$. Cases were 760 patients (580 men, 180 women; median age 61 years, range 19-79 years) with a first episode of non-fatal AMI, defined according to the WHO criteria ${ }^{(19)}$, and admitted to a network of teaching and general hospitals in the area. Controls were 682 patients (439 men, 243 women; median age 59 years, range 16-79 years) from the same area, admitted to the same hospitals for a wide spectrum of acute non-neoplastic conditions, unrelated to known AMI risk factors or dietary modification. Individuals with previous major cardiovascular events were not included. Among controls, 30\% had traumas, $25 \%$ had non-traumatic orthopaedic disorders, $18 \%$ had acute surgical conditions, $18 \%$ had eye, nose, throat or teeth disorders and 9\% had miscellaneous other illnesses unrelated to diet. Less than $5 \%$ of the cases and controls approached refused to participate.

The study was conducted according to the guidelines laid down in the Declaration of Helsinki. Verbal informed consent was obtained from all patients. Verbal consent was witnessed and formally recorded.

Interviews were conducted in hospital using a structured questionnaire, including information on sociodemographic factors, anthropometric variables, smoking, alcohol and coffee consumption, other lifestyle habits, physical activity, a problem-oriented medical history and history of AMI in first-degree relatives. Cholesterol levels were obtained from clinical records.

The participants' usual diet during the two years prior to AMI or hospital admission (for controls) was assessed through an FFQ, administered face-to-face and tested for reproducibility $^{(20)}$ and validity ${ }^{(21)}$. Participants were asked to indicate their average weekly frequency of consumption of seventy-eight foods, recipes and beverages. An Italian food composition database was used to estimate total energy and nutrient intakes ${ }^{(22,23)}$.

\section{Mediterranean diet score}

Adherence to the traditional Mediterranean diet was assessed through an a priori score (i.e. Mediterranean diet score, MDS) based on nine dietary components typical of the traditional Mediterranean diet ${ }^{(4)}$. For each study participant, a value of 0 or 1 was assigned to each component of the score as follows: for components frequently consumed in the traditional Mediterranean diet (i.e. vegetables, legumes, fruit and nuts, cereals, fish and seafood, as well a high ratio MUFA:SFA), participants whose consumption was above the sex-specific median, calculated among controls, were assigned a value of 1 , and 0 otherwise; for components less frequently consumed in the traditional Mediterranean diet (dairy, as well as meat and meat products), participants whose consumption was above the sex-specific median among controls were assigned a value of 0 , and 1 otherwise. For alcohol, a value of 1 was attributed to moderate drinkers (i.e. participants with consumption below the sex-specific median values, calculated among controls who were drinkers; these were 15.5 drinks/week for men and 7 drinks/week for women), and a value of 0 to those with consumption above these values, as well as to non-drinkers. The MDS was then calculated by summing up the points for each of the nine items. Thus, the score ranged between 0 (lowest adherence to the Mediterranean diet) and 9 (highest adherence).

\section{Data analysis}

The association of the MDS (in categories, as well as for 1-point increase) with the risk of non-fatal AMI was assessed in the overall population, as well as in strata of selected covariates, through multiple logistic regression models, which included terms for age (5-year age groups; categorically), sex, education $(<7,7-11, \geq 12$ years; categorically), BMI (quintiles among controls; categorically), cholesterol ( $<200,201-236, \geq 237 \mathrm{mg} / \mathrm{dl}$; categorically), smoking (never smokers, former smokers, current smokers of $<15$ and $\geq 15$ cigarettes/d; categorically), coffee $(<10$, $10-20, \geq 21 \mathrm{cups} / \mathrm{d}$; categorically), non-alcohol energy intake (quintiles among controls; categorically), occupational physical activity (very heavy, heavy, average, standing, mainly sitting; categorically), history of hyperlipidaemia (no, yes), diabetes (no, yes), hypertension (no, yes) and family history of AMI in first-degree relatives $(0,1, \geq 2$ affected relatives; categorically). The association of a 1-point increase in the MDS was assessed including in the model a term for the original score in continuous. Multiple logistic regression models with the same set of covariates were used to estimate the associations of the single dietary components of the MDS with non-fatal AMI, comparing participants with intake above $v$. those with intake below the corresponding sex-specific median. For alcohol intake, we estimated the association with nonfatal AMI for moderate drinkers $v$. non-drinkers or heavy drinkers.

The test for trend was based on the likelihood ratio test between models with and without a linear term for subsequent categories of the MDS (i.e. <4, 4-5, $\geq 6$ ). To investigate whether the effect of the MDS was homogeneous across strata of selected covariates, we conducted analyses stratified by age, sex, education, smoking, BMI, history of hypertension, diabetes, hyperlipidaemia, family history of AMI and non-alcohol energy intake. To test for heterogeneity between strata, the difference between the $-2 \log ($ likelihood) of the models with and without the 
interaction terms was compared with the $\chi^{2}$ distribution with the same number of degrees of freedom as the number of interaction terms.

Statistical analyses were performed using the statistical software package SAS version $9 \cdot 1$.

\section{Results}

Table 1 gives the distribution of cases with non-fatal AMI and controls according to age, sex and other characteristics. Cases were more often smokers of fifteen or more cigarettes daily and reported more often a history of hypertension and diabetes, and a family history of AMI in first-degree relatives.

Table 2 shows the OR of non-fatal AMI for each MDS component, comparing participants over the median value of each item with those below the median. The risk of non-fatal AMI was inversely related to the consumption of vegetables $(\mathrm{OR}=0.67 ; 95 \% \mathrm{CI} 0.52,0.85)$ and legumes
$(\mathrm{OR}=0.75 ; 95 \% \mathrm{CI} 0.59,0.95)$. A reduced risk of borderline significance was found for a high consumption of fruits and nuts $(\mathrm{OR}=0.80 ; 95 \% \mathrm{CI} 0.63,1.02)$. No association was observed for the other dietary items considered, including fish consumption and moderate alcohol intake.

The association of MDS with non-fatal AMI risk is presented in Table 3. Decreasing OR were found for increasing scores: as compared with MDS $<4$, the OR from the fully adjusted model were 0.85 (95\% CI 0.65 , 1.12) for MDS of $4-5$ and 0.55 (95\% CI $0.40,0.75)$ for MDS $\geq 6$, with a significant trend in risk $(P<0 \cdot 01)$. The OR for the increase of 1 point in the MDS was $0.91(95 \%$ CI $0.85,0.98$ ).

In stratified analyses (Table 4), risk estimates were consistent according to age, sex, smoking, history of selected conditions and other characteristics; a somewhat stronger association emerged for individuals with a BMI below the median (i.e. $25 \cdot 7 \mathrm{~kg} / \mathrm{m}^{2}$ ) than for those with a higher BMI ( $P$ for interaction $=0 \cdot 03$ ).

Table 1 Distribution of 760 cases of non-fatal acute myocardial infarction and 682 controls according to age, sex and other characteristics. Milan, Italy, 1995-2003

\begin{tabular}{|c|c|c|c|c|}
\hline & \multicolumn{2}{|c|}{ Cases } & \multicolumn{2}{|c|}{ Controls } \\
\hline & $n$ & $\%$ & $n$ & $\%$ \\
\hline \multicolumn{5}{|l|}{ Age (years) } \\
\hline$<50$ & 140 & 18.4 & 168 & 24.6 \\
\hline $50-59$ & 198 & $26 \cdot 1$ & 187 & $27 \cdot 4$ \\
\hline $60-69$ & 293 & 38.6 & 224 & $32 \cdot 8$ \\
\hline$\geq 70$ & 129 & $17 \cdot 0$ & 103 & $15 \cdot 1$ \\
\hline \multicolumn{5}{|l|}{ Sex } \\
\hline Men & 580 & $76 \cdot 3$ & 439 & 64.4 \\
\hline Women & 180 & $23 \cdot 7$ & 243 & 35.6 \\
\hline \multicolumn{5}{|l|}{ Education (years) ${ }^{*}$} \\
\hline$<7$ & 321 & 42.9 & 308 & 45.8 \\
\hline $7-11$ & 239 & 31.9 & 222 & 33.0 \\
\hline$\geq 12$ & 189 & $25 \cdot 2$ & 142 & $21 \cdot 1$ \\
\hline \multicolumn{5}{|l|}{ Smoking habit } \\
\hline Never smoker & 235 & $30 \cdot 9$ & 288 & $42 \cdot 2$ \\
\hline Ex smoker & 190 & 25.0 & 188 & 27.6 \\
\hline Current smoker & 335 & 44.0 & 206 & $30 \cdot 2$ \\
\hline$<15$ cigarettes/d & 77 & $10 \cdot 1$ & 76 & $11 \cdot 1$ \\
\hline$\geq 15$ cigarettes $/ d$ & 258 & 33.9 & 130 & $19 \cdot 1$ \\
\hline \multicolumn{5}{|l|}{ BMI (quintilest)* } \\
\hline 1 & 113 & 14.9 & 136 & 19.9 \\
\hline II & 173 & $22 \cdot 8$ & 137 & $20 \cdot 1$ \\
\hline III & 142 & 18.7 & 134 & $19 \cdot 6$ \\
\hline IV & 180 & 23.7 & 134 & $19 \cdot 6$ \\
\hline $\mathrm{V}$ & 151 & 19.9 & 139 & 20.4 \\
\hline \multicolumn{5}{|c|}{ History of hypertension } \\
\hline No & 519 & $68 \cdot 3$ & 513 & $75 \cdot 2$ \\
\hline Yes & 241 & 31.7 & 169 & 24.8 \\
\hline \multicolumn{5}{|l|}{ History of diabetes } \\
\hline No & 650 & 85.5 & 644 & 94.4 \\
\hline Yes & 110 & 14.5 & 38 & 5.6 \\
\hline \multicolumn{5}{|c|}{ History of hyperlipidaemia } \\
\hline No & 566 & 74.5 & 496 & $72 \cdot 7$ \\
\hline & 194 & $25 \cdot 2$ & 186 & $27 \cdot 3$ \\
\hline \multicolumn{5}{|c|}{ Family history of acute myocardial infarction } \\
\hline No & 511 & $67 \cdot 2$ & 557 & $81 \cdot 7$ \\
\hline Yes & 249 & $32 \cdot 8$ & 125 & $18 \cdot 3$ \\
\hline
\end{tabular}

*The sum does not add up to the total because of missing values.

†Quintiles among controls only. Cut-off points $\left(\mathrm{kg} / \mathrm{m}^{2}\right): 22 \cdot 85,24 \cdot 97,26 \cdot 5$ and $29 \cdot 38$. 
Table 2 Odds ratios and $95 \%$ confidence intervals of non-fatal acute myocardial infarction for single components of the Mediterranean diet score. Milan, Italy, 1995-2003

\begin{tabular}{|c|c|c|c|c|c|c|}
\hline & \multicolumn{2}{|c|}{ Median intake (portions/week) ${ }^{\star}$} & \multirow[b]{2}{*}{ OR† } & \multirow[b]{2}{*}{$95 \% \mathrm{Cl}$} & \multirow[b]{2}{*}{ OR $\ddagger$} & \multirow[b]{2}{*}{$95 \% \mathrm{Cl}$} \\
\hline & Men & Women & & & & \\
\hline \multicolumn{7}{|l|}{ Components } \\
\hline Vegetables & $9 \cdot 0$ & $10 \cdot 2$ & 0.66 & $0.54,0.82$ & 0.67 & $0.52,0.85$ \\
\hline Legumes & 1.0 & 1.0 & 0.79 & $0.64,0.98$ & 0.75 & $0.59,0.95$ \\
\hline Fruits and nuts & $15 \cdot 3$ & $17 \cdot 0$ & 0.78 & $0.63,0.97$ & 0.80 & $0.63,1.02$ \\
\hline Cereals & $30 \cdot 6$ & 23.5 & 0.98 & $0.80,1.21$ & $1 \cdot 11$ & $0.84,1.45$ \\
\hline Fish & 1.8 & 1.6 & 0.96 & $0.78,1.19$ & 0.97 & $0.77,1.23$ \\
\hline MUFA:SFA & 1.5 & 1.4 & 0.87 & $0.71,1.08$ & 0.88 & $0.70,1.12$ \\
\hline Alcohol & 14.0 & 1.0 & 1.07 & $0.86,1.34$ & 0.99 & $0.78,1.26$ \\
\hline Meat & 7.9 & $6 \cdot 0$ & 1.04 & $0.84,1.29$ & 1.06 & $0.82,1.36$ \\
\hline Dairy products & 9.2 & $10 \cdot 7$ & 0.95 & $0.77,1.17$ & 0.97 & $0.76,1.23$ \\
\hline
\end{tabular}

*Sex-specific median values are calculated among controls only.

†Adjusted for age and sex.

‡Adjusted for age, sex, education, BMI, cholesterol, smoking, coffee, energy intake (excluding alcohol), physical activity, hyperlipidaemia, diabetes, hypertension and family history of acute myocardial infarction in first-degree relatives. Estimates for moderate $v$. non-drinkers or heavy drinkers (for alcohol), and for intake over $v$. below the median (for other food items).

Table 3 Distribution of 760 cases of non-fatal acute myocardial infarction and 682 controls, odds ratios and $95 \%$ confidence intervals for the Mediterranean diet score. Milan, Italy, 1995-2003

\begin{tabular}{|c|c|c|c|c|c|c|c|c|}
\hline & \multicolumn{2}{|c|}{ Cases } & \multicolumn{2}{|c|}{ Controls } & \multirow[b]{2}{*}{$\mathrm{OR}^{*}$} & \multirow[b]{2}{*}{$95 \% \mathrm{Cl}$} & \multirow[b]{2}{*}{ OR $†$} & \multirow[b]{2}{*}{$95 \% \mathrm{Cl}$} \\
\hline & $n$ & $\%$ & $n$ & $\%$ & & & & \\
\hline \multicolumn{9}{|c|}{ Mediterranean diet score $\ddagger$ (approximate tertiles) } \\
\hline$<4$ & 274 & $36 \cdot 2$ & 212 & $31 \cdot 1$ & 1.00 & - & 1.00 & - \\
\hline $4-5$ & 320 & $42 \cdot 3$ & 267 & $39 \cdot 1$ & 0.91 & $0.71,1 \cdot 17$ & 0.85 & $0.65,1 \cdot 12$ \\
\hline$\geq 6$ & 163 & 21.5 & 203 & $29 \cdot 8$ & 0.57 & $0.43,0.75$ & 0.55 & $0.40,0.75$ \\
\hline$\chi$-trend and $P$ value & & & & & 14.46 & $<0.01$ & $13 \cdot 30$ & $<0.01$ \\
\hline Continuous OR§ & & & & & 0.92 & $0.86,0.98$ & 0.91 & $0.85,0.98$ \\
\hline
\end{tabular}

${ }^{*}$ Adjusted for age and sex.

†Adjusted for age, sex, education, BMI, cholesterol, smoking, coffee, energy intake (excluding alcohol), physical activity, hyperlipidaemia, diabetes, hypertension and family history of acute myocardial infarction in first-degree relatives.

$\ddagger$ The sum does not add up to the total because of three missing values on one score's component (i.e. alcohol).

$\S$ Continuous OR is for an increase of 1 point in the Mediterranean diet score.

\section{Discussion}

Adherence to the traditional Mediterranean diet, as indicated by the MDS, was significantly associated with a reduced risk of non-fatal AMI, after controlling for possible confounding influences by known risk factors for AMI. Specifically, an MDS of 6-9 was associated with a $45 \%$ lower incidence of non-fatal AMI compared with an MDS of $0-3$. The association was consistent among strata of various covariates, although apparently stronger in underweight and normal-weight individuals. Among the nine nutritional components of the MDS, only vegetables and legumes were associated with a reduced risk of non-fatal AMI, supporting the view that the Mediterranean diet should be evaluated as an integral entity. Previous in-depth analysis on a subgroup of participants from the same study showed that fish intake separately from other components was inversely related to non-fatal AMI only at relatively higher doses, such as $\geq 2$ portions/week $^{(17)}$. For alcohol intake, in the same data set we found that moderate and heavy drinkers had a lower risk of non-fatal AMI compared with non drinkers, with a linear trend in risk. This is in line with the present results showing similar risks in moderate drinkers compared with the combination of heavy drinkers and non-drinkers ${ }^{(24)}$.

With regard to strengths and limitations of the present study, cases and controls were interviewed in the same hospitals and came from the same geographical area, participation was almost complete, patients admitted for chronic conditions or diseases related to known or potential risk factors for AMI or modification of diet were excluded from the comparison group, and the FFQ was satisfactorily valid $^{(21)}$ and reproducible ${ }^{(25)}$. We cannot exclude that a generally healthier lifestyle may play a role in the inverse association of adherence to the Mediterranean diet with AMI risk. However, we paid attention to adjust for the potential confounding of covariates associated with AMI risk, such as physical activity, BMI, smoking and energy intake. A major strength of the present study is the strict and validated definition of AMI, since all cases were admitted to reference centres for heart diseases. 
Table 4 Number of cases/controls, odds ratios* and $95 \%$ confidence intervals of non-fatal acute myocardial infarction for scores of the Mediterranean diet in strata of selected covariates. Milan, Italy, 1995-2003

\begin{tabular}{|c|c|c|c|c|c|c|c|c|c|}
\hline & \multicolumn{9}{|c|}{ Mediterranean diet score } \\
\hline & \multirow[t]{2}{*}{$<4 \dagger$} & \multicolumn{2}{|r|}{$4-5$} & \multicolumn{2}{|r|}{$\geq 6$} & \multicolumn{2}{|c|}{ Continuous term $\ddagger$} & \multirow[b]{2}{*}{$\chi$-trend } & \multirow[b]{2}{*}{$P$ value } \\
\hline & & OR & $95 \% \mathrm{Cl}$ & OR & $95 \% \mathrm{Cl}$ & OR & $95 \% \mathrm{Cl}$ & & \\
\hline \multicolumn{10}{|l|}{ Age (years) } \\
\hline$<60$ & $128 / 1051$ & & $132 / 151$ & & $69 / 99$ & & & & \\
\hline & & 0.61 & $\begin{array}{c}0.40,0.92 \\
182 / 116\end{array}$ & 0.45 & $\begin{array}{l}0.28,0.74 \\
94 / 104\end{array}$ & 0.86 & $0.77,0.96$ & $10 \cdot 2$ & $<0.01$ \\
\hline $\begin{array}{l}\geq 60 \\
P \S=0 \cdot 13\end{array}$ & $146 / 1071$ & $1 \cdot 15$ & $0.79,1.66$ & 0.64 & $0.42,0.97$ & 0.95 & $0.87,1.05$ & 3.62 & 0.06 \\
\hline \multicolumn{10}{|l|}{$\begin{array}{l}P \S=0.13 \\
\text { Sex }\end{array}$} \\
\hline Male & 205/1291 & & $237 / 174$ & & $136 / 136$ & & & & \\
\hline Female & $69 / 831$ & 0.82 & $\begin{array}{l}0.59,1 \cdot 14 \\
83 / 93\end{array}$ & 0.56 & $\begin{array}{l}0.39,0.81 \\
27 / 69\end{array}$ & 0.93 & $0.85,1.01$ & $9 \cdot 3$ & $<0.01$ \\
\hline$P=0.48$ & & 1.00 & $0.59,1.72$ & 0.52 & $0.26,1.02$ & 0.88 & $0.76,1.02$ & $2 \cdot 9$ & 0.09 \\
\hline \multicolumn{10}{|l|}{ Education (years) } \\
\hline$<7$ & $124 / 1011$ & & $142 / 126$ & & $65 / 91$ & & & & \\
\hline$\geq 7$ & $150 / 1111$ & 0.83 & $\begin{array}{c}0.55,1.25 \\
178 / 141\end{array}$ & 0.46 & $\begin{array}{l}0.28,0.77 \\
98 / 112\end{array}$ & 0.90 & $0.80,1.00$ & $8 \cdot 3$ & $<0.01$ \\
\hline$P=0.89$ & & 0.85 & $0.59,1.24$ & 0.57 & $0.37,0.87$ & 0.92 & $0.83,1.01$ & $6 \cdot 7$ & 0.01 \\
\hline \multicolumn{10}{|l|}{$\begin{array}{l}r=0.89 \\
\text { Smoking }\end{array}$} \\
\hline Non smokers & $140 / 1401$ & & $185 / 188$ & & $99 / 148$ & & & & \\
\hline Current smokers & $134 / 721$ & 0.83 & $\begin{array}{c}0.59,1 \cdot 18 \\
135 / 79\end{array}$ & 0.55 & $\begin{array}{l}0.36,0.82 \\
64 / 55\end{array}$ & 0.91 & $0.83,1.00$ & 8.4 & $<0.01$ \\
\hline$P=0.83$ & & 0.90 & $0.57,1.42$ & 0.56 & $0.32,0.96$ & 0.93 & $0.82,1.05$ & 3.9 & 0.05 \\
\hline \multicolumn{10}{|l|}{$\begin{array}{c}P=0.83 \\
\mathrm{BMl}\left(\mathrm{kg} / \mathrm{m}^{2}\right)\end{array}$} \\
\hline$\leq 25 \cdot 7 \|$ & $140 / 1171$ & & $149 / 126$ & & $58 / 96$ & & & & \\
\hline$>25 \cdot 7 \|$ & $134 / 951$ & 0.89 & $\begin{array}{c}0.60,1 \cdot 31 \\
171 / 141\end{array}$ & 0.38 & $\begin{array}{c}0.23,0.61 \\
105 / 107\end{array}$ & 0.87 & $0.78,0.97$ & $13 \cdot 4$ & $<0.01$ \\
\hline$P=0.03$ & & 0.79 & $0.54,1.16$ & 0.69 & $0.44,1.06$ & 0.94 & $0.86,1.04$ & $2 \cdot 9$ & 0.09 \\
\hline \multicolumn{10}{|c|}{ History of hypertension } \\
\hline No & 201/1771 & & $215 / 196$ & & $100 / 140$ & & & & \\
\hline Yes & $73 / 351$ & 0.92 & $\begin{array}{c}0.67,1 \cdot 27 \\
105 / 71\end{array}$ & $0 \cdot 61$ & $\begin{array}{l}0.42,0.90 \\
63 / 63\end{array}$ & 0.94 & $0.87,1.03$ & $5 \cdot 7$ & 0.02 \\
\hline$P=0.57$ & & 0.73 & $0.41,1.30$ & 0.42 & $0.22,0.79$ & 0.86 & $0.75,0.99$ & 7.5 & 0.01 \\
\hline \multicolumn{10}{|l|}{$\begin{array}{l}P=0.57 \\
\text { History of diabetes }\end{array}$} \\
\hline No & 238/2031 & & $267 / 250$ & & $142 / 191$ & & & & \\
\hline Yes & $36 / 91$ & 0.84 & $\begin{array}{l}0.63,1.11 \\
53 / 17\end{array}$ & 0.55 & $\begin{array}{l}0.39,0.77 \\
21 / 12\end{array}$ & 0.91 & $0.85,0.98$ & $11 \cdot 8$ & $<0.01$ \\
\hline$P=0.68$ & & $0 \cdot 75$ & $0 \cdot 20,2 \cdot 84$ & 0.40 & $0.08,1.83$ & 0.88 & $0.61,1 \cdot 27$ & $1 \cdot 3$ & 0.25 \\
\hline \multicolumn{10}{|c|}{ History of hyperlipidaemia } \\
\hline No & $220 / 1801$ & & $240 / 186$ & & $104 / 130$ & & & & \\
\hline Yes & $54 / 321$ & 0.96 & $\begin{array}{l}0 \cdot 70,1 \cdot 31 \\
80 / 81\end{array}$ & 0.56 & $\begin{array}{l}0.38,0.82 \\
59 / 73\end{array}$ & 0.93 & $0.86,1.02$ & 7.4 & 0.01 \\
\hline$P=0.68$ & & 0.70 & $0.37,1.31$ & 0.55 & $0.28,1.07$ & 0.90 & $0.77,1.04$ & $3 \cdot 1$ & 0.08 \\
\hline \multicolumn{10}{|c|}{$\begin{array}{l}P=0.68 \\
\text { Family history of acute myocardial infarction }\end{array}$} \\
\hline No & $194 / 1761$ & & $202 / 213$ & & $112 / 168$ & & & & \\
\hline Yes & $80 / 361$ & 0.80 & $\begin{array}{l}0.58,1.09 \\
118 / 54\end{array}$ & 0.48 & $\begin{array}{l}0.34,0.70 \\
51 / 35\end{array}$ & 0.89 & $0.82,0.97$ & $14 \cdot 8$ & $<0.01$ \\
\hline$P=0.57$ & & $1 \cdot 15$ & $0.64,2.08$ & $0 \cdot 88$ & $0.43,1.79$ & 1.03 & $0.88,1 \cdot 21$ & 0.08 & 0.77 \\
\hline \multicolumn{10}{|c|}{ Non-alcohol energy $(\mathrm{kJ})$} \\
\hline$\leq 90699$ & $152 / 1301$ & & $167 / 129$ & & $53 / 82$ & & & & \\
\hline$>9069$ & $112 / 821$ & 0.96 & $\begin{array}{c}0.65,1.41 \\
153 / 138\end{array}$ & 0.43 & $\begin{array}{l}0.26,0.70 \\
110 / 121\end{array}$ & 0.93 & $0.84,1.04$ & $8 \cdot 7$ & $<0.01$ \\
\hline$P=0.17$ & 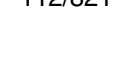 & 0.67 & $0.45,1.02$ & 0.56 & $0.36,0.87$ & 0.97 & $0.79,0.97$ & $6 \cdot 4$ & 0.01 \\
\hline
\end{tabular}

*Adjusted for age, sex, education, BMI, cholesterol, smoking, coffee, energy intake (excluding alcohol), physical activity, hyperlipidaemia, diabetes, hypertension and family history of acute myocardial infarction in first-degree relatives, when appropriate.

†Reference category $(\mathrm{OR}=1.00)$.

$\ddagger$ Continuous OR is for an increase of 1 point in the Mediterranean diet score.

$\S P$ for interaction test.

$\| 25.7 \mathrm{~kg} / \mathrm{m}^{2}$ is the median value of BMl among controls.

\9069 kJ (2166 kcal) is the median value of daily non-alcohol energy among controls. 
Our findings are consistent with previous investigations evaluating adherence with the Mediterranean diet in relation to $\mathrm{CHD}^{(2,6,15,16)}$. In particular, using data from the Greek component of the European Prospective Investigation into Cancer and Nutrition (EPIC) cohort, Dilis et al. found that a 2-point increase in the MDS was associated with significantly lower CHD incidence (hazard ratio $(\mathrm{HR})=$ 0.85; $95 \%$ CI 0.57, 0.98) among women but not among men, and with significantly lower CHD mortality by $25 \%(\mathrm{HR}=0.75 ; 95 \% \mathrm{CI} 0.57,0.98)$ among women and $19 \%(\mathrm{HR}=0.81 ; 95 \% \mathrm{CI} 0.67,0.99)$ among men ${ }^{(26)}$. On the same cohort, increased adherence to the Mediterranean diet was inversely associated with cerebrovascular disease incidence and mortality ${ }^{(14)}$. In the EPIC-NL cohort study, based on 34708 participants followed for 10-15 years for a total of 4881 CVD events and 487 deaths from CVD, a 2-unit increment in the MDS (in which the component of moderate alcohol consumption was substituted by any consumption because of the relatively low levels of alcohol consumption in that population) was inversely associated with fatal CVD ( $\mathrm{HR}=0.78$; $95 \% \mathrm{CI}$ 0.69, 0.88), total CVD ( $\mathrm{HR}=0.95 ; 95 \%$ CI 0.91, 0.98), myocardial infarction $(\mathrm{HR}=0.86 ; 95 \% \mathrm{CI} 0.79,0.93)$ and stroke $(\mathrm{HR}=0.88 ; 95 \% \mathrm{CI} 0.78,1.00)^{(27)}$. In the SUN (Seguimiento University of Navarra) study, a prospective ongoing dynamic cohort of university Spanish graduates, participants with the highest adherence to the Mediterranean diet showed a $59 \%$ significantly lower risk of CVD than those with the lowest adherence. Similar point estimates, but wider confidence intervals, were estimated for $\mathrm{CHD}^{(28)}$. In a multi-ethnic, population-based, prospective cohort study from the USA (the Northern Manhattan Study), a Mediterranean dietary pattern, summarized by the MDS, was protective against a combined outcome of ischaemic stroke, myocardial infarction and vascular death (HR $=0.75 ; 95 \%$ CI 0.56, 0.99 for MDS of 6-9 $v$. MDS of $0-2)^{(29)}$. Results for myocardial infarction alone were less clear cut, but were based on 133 cases only ${ }^{(29)}$. Based on 2391 incident CHD cases and 794 CHD deaths occurring in the Nurses' Health Study, a lower risk of both CHD incidence (relative risk $(\mathrm{RR})=0.71 ; 95 \%$ CI $0.62,0.82$ ) and CHD mortality $(\mathrm{RR}=0.58 ; 95 \% \mathrm{CI} 0.45,0.75)$ emerged for women in the highest quintile as compared with those in the lowest quintile of an alternative MDS, based on the following components: high consumption of vegetables (excluding potatoes), fruits, nuts, whole grains, legumes and fish; high ratio MUFA:SFA; low consumption of red and processed meats; and moderate alcohol intake ${ }^{(30)}$. Also the Spanish EPIC component investigated the association between CHD and the Mediterranean diet, measured by using a variation of the original MDS. A high MDS was associated with a significant reduction in CHD risk ( $\mathrm{HR}=0.60 ; 95 \%$ CI $0.47,0.77)$ compared with a low score $^{(31)}$. Moreover, a 1 -unit increase in the MDS was associated with a $6 \%$ significant reduced risk of $\mathrm{CHD}^{(31)}$, similar to our result of a $9 \%$ reduction of risk of AMI.
Reports focused exclusively on mortality from CHD found, in general, a lower risk for a closer adherence to the Mediterranean diet ${ }^{(4,32-34)}$. Evidence for a cardioprotective effect of the Mediterranean diet also emerged from studies showing an improvement in the prognosis of coronary patients, including mortality ${ }^{(35-39)}$, and from intervention studies showing a reduction in the prevalence of cardiovascular events in high-risk individuals ${ }^{(40)}$ and CVD risk factors, such as high BMI, systolic blood pressure, plasma glucose, C-reactive protein, cholesterol levels and $\mathrm{TAG}^{(41-43)}$.

The idea that the Mediterranean diet could be favourable for health came from the observation in the early 1960s that the populations living in Crete, Greece and southern Italy were particularly healthy ${ }^{(44)}$. Mediterranean diet main characteristics are that a large proportion of energy comes from cereals and starchy foods, such as bread, pasta, rice and potatoes; most fat is represented by olive oil; it is rich in plant foods, including raw and cooked vegetables, fruit, legumes and nuts; it contains moderate intakes of fish, poultry and cheese and a low intake of red meat; alcohol is represented by wine in moderate amount and mainly consumed at meals ${ }^{(45)}$. In terms of nutrients, the Mediterranean diet is low in SFA, high in MUFA and oleic acid (mainly from olive oil), high in complex carbohydrates (from legumes) and high in fibre (mostly from vegetables, fruit, cereals and legumes). The high content of vegetables, fresh fruits, cereals and olive oil implies a high intake of $\beta$-carotene, vitamins $\mathrm{C}$ and $\mathrm{E}$, folates, flavonoids and polyphenols, and of various important minerals including potassium. These food components and nutrients have been indicated as responsible for the beneficial effect of diet on human health and in particular on $\mathrm{CVD}^{(2,4,6)}$. However, despite a strong inverse association between the Mediterranean diet and CVD risk, individual components are not or weakly inversely related with the risk $^{(4)}$. This may be due to the fact that the benefit of each component is too small to be detected, or that the effect of single components is synergistic with that of the others and consequently an interaction between several components is necessary for a significant favourable effect. That the Mediterranean diet is biologically compatible with a favourable effect on CVD risk is biologically plausible. It has been related with lower endothelial dysfunction and biomarker effects ${ }^{(46)}$ and with higher adiponectin levels ${ }^{(47)}$ in the Nurses' Health Study, and with lower blood pressure in the EPIC study ${ }^{(48)}$. It may also protect against coronary artery wall production of inflammatory mediators in patients with unstable angina ${ }^{(49)}$, is inversely associated with IL-6 levels in middle-aged men ${ }^{(50)}$, and is related to elevated non-enzymatic total antioxidant capacity and low oxidized LDL-cholesterol concentrations ${ }^{(51)}$. In a 2 -year trial, the Mediterranean diet reduced the prevalence of the metabolic syndrome and its associated cardiovascular risk $^{(52)}$, and in a 3-month intervention study it reduced lipoprotein oxidation ${ }^{(42)}$ and more generally had beneficial effects on cardiovascular risk factors ${ }^{(43)}$. 


\section{Conclusion}

In conclusion, in this Southern European population we found that adherence to the Mediterranean diet is associated with a lower risk of AMI, a leading cause of death in most countries. This adds to the growing body of evidence supporting the beneficial effects on health of this dietary pattern.

\section{Acknowledgements}

Acknowledgements: The authors thank Mrs Ivana Garimoldi for editorial assistance. Financial support: This work was supported by the contribution of the Italian Association for Cancer Research (AIRC) (grant number 10068). G.C. was supported by a Fellowship from Fondazione Umberto Verones. ARIC and Fondazione Umberto Verones had no role in the design, analysis or writing of this article. Conflict of interest: None. Authorship: C.L.V. designed the research and provided overall research supervision; C.L.V. and A.T. conducted the research; F.T. and C.P. analysed the data; F.T. drafted the manuscript; C.P., C.G., D.P. and A.T. contributed to interpretation of the data and revising the paper. All authors read and approved the final manuscript. Ethics of buman subject participation: Ethical approval was not required.

\section{References}

1. Keys AB \& Aravanis C (1980) Seven Countries: A Multivariate Analysis of Death and Coronary Heart Disease. Cambridge, MA: Harvard University Press.

2. Mente A (2009) A systematic review of the evidence supporting a causal link between dietary factors and coronary heart disease. Arch Intern Med 169, 659-669.

3. World Health Organization (2003) Diet, Nutrition and the Prevention of Chronic Diseases. WHO Technical Report Series no. 916. Geneva: WHO.

4. Trichopoulou A, Costacou T, Bamia C et al. (2003) Adherence to a Mediterranean diet and survival in a Greek population. N Engl J Med 348, 2599-2608.

5. Lagiou P, Trichopoulos D, Sandin S et al. (2006) Mediterranean dietary pattern and mortality among young women: a cohort study in Sweden. Br J Nutr 96, 384-392.

6. Sofi F, Abbate R, Gensini GF et al. (2010) Accruing evidence on benefits of adherence to the Mediterranean diet on health: an updated systematic review and meta-analysis. $\mathrm{Am}$ J Clin Nutr 92, 1189-1196.

7. Benetou V, Trichopoulou A, Orfanos P et al. (2008) Conformity to traditional Mediterranean diet and cancer incidence: the Greek EPIC cohort. Br J Cancer 99, 191-195.

8. Trichopoulou A, Lagiou P, Kuper H et al. (2000) Cancer and Mediterranean dietary traditions. Cancer Epidemiol Biomarkers Prev 9, 869-873.

9. La Vecchia C \& Bosetti C (2006) Diet and cancer risk in Mediterranean countries: open issues. Public Health Nutr 9 , 1077-1082.

10. Bosetti C, Gallus S, Trichopoulou A et al. (2003) Influence of the Mediterranean diet on the risk of cancers of the upper aerodigestive tract. Cancer Epidemiol Biomarkers Prev 12, 1091-1094
11. Trichopoulou A, Bamia C, Lagiou P et al. (2010) Conformity to traditional Mediterranean diet and breast cancer risk in the Greek EPIC (European Prospective Investigation into Cancer and Nutrition) cohort. Am J Clin Nutr 92, 620-625.

12. Reedy J, Mitrou PN, Krebs-Smith SM et al. (2008) Indexbased dietary patterns and risk of colorectal cancer: the NIH-AARP Diet and Health Study. Am J Epidemiol 168, $38-48$.

13. Buckland G, Agudo A, Lujan L et al. (2010) Adherence to a Mediterranean diet and risk of gastric adenocarcinoma within the European Prospective Investigation into Cancer and Nutrition (EPIC) cohort study. Am J Clin Nutr 91, 381-390.

14. Misirli G, Benetou V, Lagiou P et al. (2012) Relation of the traditional Mediterranean diet to cerebrovascular disease in a Mediterranean population. Am J Epidemiol 176, 1185-1192.

15. Panagiotakos DB, Pitsavos C, Polychronopoulos E et al. (2004) Can a Mediterranean diet moderate the development and clinical progression of coronary heart disease? A systematic review. Med Sci Monit 10, RA193-RA198.

16. Tyrovolas S \& Panagiotakos DB (2010) The role of Mediterranean type of diet on the development of cancer and cardiovascular disease, in the elderly: a systematic review. Maturitas 65, 122-130.

17. Tavani A, Pelucchi C, Negri E et al. (2001) n-3 Polyunsaturated fatty acids, fish, and nonfatal acute myocardial infarction. Circulation 104, 2269-2272.

18. Tavani A, Gallus S, Negri E et al. (2006) Dietary intake of carotenoids and retinol and the risk of acute myocardial infarction in Italy. Free Radic Res 40, 659-664.

19. World Health Organization (1971) Ischemic Heart Disease Registers. Report of the Fifth Working Group. Copenhagen: WHO Regional Office for Europe.

20. Franceschi S, Barbone F, Negri E et al. (1995) Reproducibility of an Italian food frequency questionnaire for cancer studies. Results for specific nutrients. Ann Epidemiol 5, 69-75.

21. Decarli A, Franceschi S, Ferraroni M et al. (1996) Validation of a food-frequency questionnaire to assess dietary intakes in cancer studies in Italy. Results for specific nutrients. Ann Epidemiol 6, 110-118.

22. Salvini S, Parpinel M, Gnagnarella P et al. (1998) Banca di composizione degli alimenti per studi epidemiologici in Italia. Milano: Istituto Europeo di Oncologia.

23. Gnagnarella P, Parpinel M, Salvini S et al. (2004) The update of the Italian food composition database. J Food Compost Analysis 17, 509-522.

24. Tavani A, Bertuzzi M, Negri E et al. (2001) Alcohol, smoking, coffee and risk of non-fatal acute myocardial infarction in Italy. Eur J Epidemiol 17, 1131-1137.

25. Dauchet L, Amouyel P, Hercberg S et al. (2006) Fruit and vegetable consumption and risk of coronary heart disease: a meta-analysis of cohort studies. J Nutr 136, 2588-2593.

26. Dilis V, Katsoulis M, Lagiou P et al. (2012) Mediterranean diet and CHD: the Greek European Prospective Investigation into Cancer and Nutrition cohort. Br J Nutr 108, 699-709.

27. Hoevenaar-Blom MP, Nooyens AC, Kromhout D et al. (2012) Mediterranean style diet and 12-year incidence of cardiovascular diseases: the EPIC-NL cohort study. PLOS One 7, e45458.

28. Martinez-Gonzalez MA, Garcia-Lopez M, Bes-Rastrollo M et al. (2011) Mediterranean diet and the incidence of cardiovascular disease: a Spanish cohort. Nutr Metab Cardiovasc Dis 21, 237-244.

29. Gardener H, Wright CB, Gu Y et al. (2011) Mediterraneanstyle diet and risk of ischemic stroke, myocardial infarction, and vascular death: the Northern Manhattan Study. Am J Clin Nutr 94, 1458-1464. 
30. Fung TT, Rexrode KM, Mantzoros CS et al. (2009) Mediterranean diet and incidence of and mortality from coronary heart disease and stroke in women. Circulation 119, 1093-1100.

31. Buckland G, Gonzalez CA, Agudo A et al. (2009) Adherence to the Mediterranean diet and risk of coronary heart disease in the Spanish EPIC Cohort Study. Am J Epidemiol 170, 1518-1529.

32. Knoops KT, de Groot LC, Kromhout D et al. (2004) Mediterranean diet, lifestyle factors, and 10-year mortality in elderly European men and women: the HALE project. JAMA 292, 1433-1439.

33. Mitrou PN, Kipnis V, Thiebaut AC et al. (2007) Mediterranean dietary pattern and prediction of all-cause mortality in a US population: results from the NIH-AARP Diet and Health Study. Arch Intern Med 167, 2461-2468.

34. Brunner EJ, Mosdol A, Witte DR et al. (2008) Dietary patterns and 15 -y risks of major coronary events, diabetes, and mortality. Am J Clin Nutr 87, 1414-1421.

35. Trichopoulou A, Bamia C, Norat T et al. (2007) Modified Mediterranean diet and survival after myocardial infarction: the EPIC-Elderly study. Eur J Epidemiol 22, 871-881.

36. de Lorgeril M, Renaud S, Mamelle N et al. (1994) Mediterranean $\alpha$-linolenic acid-rich diet in secondary prevention of coronary heart disease. Lancet 343, 1454-1459.

37. de Lorgeril M, Salen P, Martin JL et al. (1999) Mediterranean diet, traditional risk factors, and the rate of cardiovascular complications after myocardial infarction: final report of the Lyon Diet Heart Study. Circulation 99, 779-785.

38. de Lorgeril, Salen P, Martin JL et al. (1998) Mediterranean dietary pattern in a randomized trial; prolonged survival and possible reduced cancer rate. Arch Intern Med 158, 1181-1185.

39. Trichopoulou A, Bamia C \& Trichopoulos D (2005) Mediterranean diet and survival among patients with coronary heart disease in Greece. Arch Intern Med 165, 929-935.

40. Estruch R, Ros E, Salas-Salvado J et al. (2013) Primary prevention of cardiovascular disease with a Mediterranean diet. N Engl J Med 368, 1279-1290.

41. Vincent-Baudry S, Defoort C, Gerber M et al. (2005) The Medi-RIVAGE study: reduction of cardiovascular disease risk factors after a 3-mo intervention with a Mediterraneantype diet or a low-fat diet. Am J Clin Nutr 82, 964-971.

42. Fito M, Guxens M, Corella D et al. (2007) Effect of a traditional Mediterranean diet on lipoprotein oxidation: a randomized controlled trial. Arch Intern Med 167, 1195-1203.

43. Estruch R, Martinez-Gonzalez MA, Corella D et al. (2006) Effects of a Mediterranean-style diet on cardiovascular risk factors: a randomized trial. Ann Intern Med 145, 1-11.

44. Hu FB (2003) The Mediterranean diet and mortality - olive oil and beyond. N Engl J Med 348, 2595-2596.

45. Willett WC, Sacks F, Trichopoulou A et al. (1995) Mediterranean diet pyramid: a cultural model for healthy eating. Am J Clin Nutr 61, 6 Suppl, 1402S-1406S.

46. Fung TT, McCullough ML, Newby PK et al. (2005) Dietquality scores and plasma concentrations of markers of inflammation and endothelial dysfunction. Am J Clin Nutr 82, 163-173.

47. Mantzoros CS, Williams CJ, Manson JE et al. (2006) Adherence to the Mediterranean dietary pattern is positively associated with plasma adiponectin concentrations in diabetic women. Am J Clin Nutr 84, 328-335.

48. Psaltopoulou T, Naska A, Orfanos P et al. (2004) Olive oil, the Mediterranean diet, and arterial blood pressure: the Greek European Prospective Investigation into Cancer and Nutrition (EPIC) study. Am J Clin Nutr 80, 1012-1018.

49. Serrano-Martinez M, Palacios M, Martinez-Losa E et al. (2005) A Mediterranean dietary style influences TNF- $\alpha$ and VCAM-1 coronary blood levels in unstable angina patients. Eur J Nutr 44, 348-354.

50. Dai J, Miller AH, Bremner JD et al. (2008) Adherence to the Mediterranean diet is inversely associated with circulating interleukin-6 among middle-aged men: a twin study. Circulation 117, 169-175.

51. Pitsavos C, Panagiotakos DB, Tzima N et al. (2005) Adherence to the Mediterranean diet is associated with total antioxidant capacity in healthy adults: the ATTICA study. Am J Clin Nutr 82, 694-699.

52. Esposito K, Marfella R, Ciotola M et al. (2004) Effect of a Mediterranean-style diet on endothelial dysfunction and markers of vascular inflammation in the metabolic syndrome: a randomized trial. JAMA 292, 1440-1446. 